\title{
Constitutive Model of Thin Metal Sheet in Bulging Test Considering Strain Gradient Hardening
}

\author{
Wei LIANG $^{1}{ }^{*}$, Tieping WEI ${ }^{2}$, Xiaoxiang YANG ${ }^{1}$ \\ ${ }^{1}$ School of Mechanical Engineering and Automation, Fuzhou University, No. 2, North Wulong River Avenue, Minhou \\ District, Fuzhou 350108, Fujian, China P.R. \\ ${ }^{2}$ Department of Mechanical and Automotive Engineering, Fujian University of Technology, No. 3, South Xuefu Road, \\ Minhou District, Fuzhou 350108, Fujian, China P.R.
}

crossref http://dx.doi.org/10.5755/j01.ms.26.4.22201

Received 05 December 2018; accepted 01 March 2019

\begin{abstract}
The study of the size effect was one of the most important subjects in the field of micro-forming. To investigate the stress of the thin sheet in the bulging test with the second order size effect, a constitutive equation considering the strain gradient hardening was proposed. Based on the equation, the stress of the thin sheet during the bulging test was calculated by the finite element method. The bulging tests with various thicknesses of brass sheets and radiuses of punching balls were performed to verify the proposed equation. The results showed that the constitutive equation could capture the stress variations, while the simulation using the constitutive equation from the conventional theory of plasticity showed the results with large deviation from those of the experiment. It was found that the stress was sensitive to the thickness of the sheet and the radius of the punching ball in bulging test of thin brass sheet. The bulging of the thin brass sheet with a thickness below ten times of its material intrinsic length would cause the generation of the geometrically necessary dislocations, which induced the strain gradient hardening. Besides that, the decrement of the punching ball radius would also increase the inhomogeneous deformation and enhance the strain gradient hardening during the thin sheet bulging process. The strain gradient hardening during the thin sheet bulging test was related to the strain of the sheet. The hardening effect of the strain gradient was obvious when the strain was small. The strain gradient hardening should be considered in the thin sheet bulging test with the second order size effect.

Keywords: size effect, constitutive, thin sheet, strain gradient, bulge.
\end{abstract}

\section{INTRODUCTION}

Thin metal sheet micro-forming process, well-known for their process simplicity, high production rate, minimized material waste, near-net-shapes, excellent mechanical properties [1, 2], and close tolerances [3], are claimed to be the most suitable process to fabricate micro-parts in the fields of electronics [4], medical devices, Micro Electro Mechanical Systems (MEMS) [5], and Micro System Technology (MST) [6-10]. However, there are challenges in the thin metal sheet forming process when the sheet thickness is decreased to the level of micrometres, because of the unknown deformation mechanics and material behaviour which called the "second order size effect" [11-15].

Many researchers have been carried out to investigate the "second order size effect" on the material strength. An increase in the flow stress was observed as N, which was the ratio of the sheet thickness to the material grain size, decreased, especially when $\mathrm{N}$ was in the range from 1 to 4 . For instance, a micro hydraulic bulging testing of the thin CuZn36 sheet by [16] found that flow stress increased as $\mathrm{N}$ value decreased from 5 to 3.3. In the bending testing of CuZn15 by [17] and aluminium $99.0 \% \sim 99.5 \%$ by [18], the phenomena of increase of the flow stress were also observed as $\mathrm{N}$ was reduced to near 1 (single crystal deformation). A series of hydraulic bulging testing of thin metal sheets with thicknesses in the range from $25 \mu \mathrm{m}$ to $500 \mu \mathrm{m}$ were carried out by [19]. The results showed that the flow stress curves were absolutely different from those obtained from the single direction tensile testing when the thickness was less than $50 \mu \mathrm{m}$.

U. Engle [9] reported that the mechanical behaviour was characterized by only a few grains located in the deformed area at micro-scale; thus, the material cannot be considered as a homogeneous continuum. The deformation behaviour of each grain plays a significant role in the entire deformation behaviour of the deformation body. So the "surface model" [20] and "modify Hall-Petch model" [21] cannot explain the special phenomenon of the second order size effect any more.

The theory of Statistically Stored Dislocations (SSD) and Geometrically Necessary Dislocations (GND) was introduced by Ashby [22,23] and developed further by Fleck [24,25] and Hutchinson [26,27,28,29,30,31,32] which suggested that strengthening is associated with the first order gradient in plastic strain. The theory was a non-linear generalisation of Cosserat couple stress theory. Tension and torsion experiments on thin copper wires confirm the presence of strain gradient hardening (SGH).

Based on the theory of the Fleck and Hutchinson, S.H. Chen, and T.C. Wang [33-38] proposed a new hardening law for strain gradient plasticity. The strain gradient plasticity was represented as an internal variable to

\footnotetext{
${ }^{*}$ Corresponding author. Tel.: +86-15005966988; fax: +86-059183753562. E-mail address: weirliang@foxmail.com (W. Liang)
} 
increase the tangent modulus. The new hardening law was demonstrated by two experimental tests i.e. thin wire torsion and ultra-thin beam bending tests. The present theoretical results agree well with the experiment results, even when the diameter of the wire decreased to $12 \mu \mathrm{m}$.

So the theory of the strain gradient is a possible tool to capture the deformation mechanics and material behaviour influenced by the second order size effect. A constitutive model, taking into accounts both plastic strain and plastic strain gradient hardening ( $\mathrm{SGH}$ ), was developed by Li et al [39] and verified by the experiments of spring back behaviour of pure aluminium foils with thickness from $25 \mu \mathrm{m}$ to $500 \mu \mathrm{m}$ very well.

Lee et al [40] found the strain gradient, which was the second derivative of displacement, played a very important role in the thin metal forming when the thickness was only several micrometres. Based on the non-homogeneity characteristics of the polycrystalline metallic materials, a modified model was proposed. And it also could capture the experiments phenomena much well [41].

In the present paper, a constitute equation, which considers the plastic strain and plastic SGH, is suggested and used to predict the stress of the thin sheet in the bulge processing. Series of the bulge experiments and finite element analysis were carried out to verify the proposed equation.

\section{CONSTITUTIVE EQUATION MODEL}

\subsection{Constitutive equation}

In the study of Ashby and Fleck [24, 26, 28, 31, 32], it is supported that dislocation was generated, moved, and stored when a plastic crystal was deformed. The storage caused the material to work harden. Dislocations became stored for two reasons: they accumulated by trapping each other in a random way or they were required for compatible deformation of various parts of the crystal. The dislocations which trap each other randomly were referred to as SSD, $\rho_{\mathrm{s}}$, which was estimated as a function of stain. The gradient of plastic shear resulted in the storage of GNS, $\rho_{\mathrm{s}}$. Plastic strain gradients appeared either because of the geometry of loading or because the material itself was plastically inhomogeneous. The GNS was evaluated by the strain gradient.

In conventional plasticity theory, there is no length scale considered in the constitutive law and no size effect is predicted. The index hardening model is expressed as the following equation,

$\sigma_{\mathrm{e}}=K \cdot \varepsilon_{\mathrm{e}}^{n}$

where $\sigma_{\mathrm{e}}$ is the flow stress; $K$ is strength coefficient; $\varepsilon_{\mathrm{e}}$ is effective strain; $n$ is the hardening index.

However, when the length scale associated with the deformation field is small compared to a material length scale, for most materials at the level of micrometres, it becomes necessary to include the strain gradient term in the constitutive equation [26]. The constitutive model is proposed as
$\sigma_{\mathrm{e}}=K \cdot \varepsilon_{\mathrm{e}}^{n}\left(1+\beta^{2} \frac{l^{2} \eta^{2}}{\varepsilon_{\mathrm{e}}^{2}}\right)$

where $l$ is the material intrinsic length; $\beta$ is a geometrical parameter, which is relative to the size of specimen; $\eta$ is the effective strain gradient. It is defined as [26]

$\eta=\left[\left(\frac{l_{1}}{l_{\mathrm{CS}}}\right)^{2} \eta_{i j k}^{(1)} \eta_{i j k}^{\prime(1)}+\chi_{\mathrm{e}}^{2}\right]^{1 / 2}$

where $l_{l}$ is the internal material intrinsic length for stretch gradient, $l_{l}=1 / 10 l[26] ; l_{c s}$ is the internal material intrinsic length for rotation gradient, $l_{c s}=l[42]$.

In Ref. [26], Fleck and Hutchinson denotes $\eta_{\mathrm{ijk}}$ as the second gradient of displacement, $u_{\mathrm{i}}$,

$\eta_{i j k}=u_{k, i j},(i, j, k=1,2,3)$;

and

$\eta_{i j k}^{(1)}=\eta_{i j k}^{s}-1 / 5\left(\delta_{i j} \eta_{k p p}^{s}+\delta_{k j} \eta_{i p p}^{s}+\delta_{i k} \eta_{j p p}^{s}\right)$ is the first deviatoric invariant of the second gradient of displacement, where

$\eta_{i j k}^{s}=1 / 3\left(\eta_{i j k}^{\prime}+\eta_{k i j}^{\prime}+\eta_{j k i}^{\prime}\right)$

$\eta_{i j k}^{\prime}=\eta_{i j k}-1 / 4\left(\delta_{i k} \eta_{j p p}+\delta_{j k} \eta_{i p p}\right), \delta_{\mathrm{y}}$ is Kronecker delta. The effective rotation strain gradient, $\chi_{\mathrm{e}}$, is the deformation curvature.

$\chi_{\mathrm{e}}=\sqrt{2 / 3 \chi_{i j} \chi_{i j}}$, in which $\chi_{\mathrm{ij}}$ is the rotation strain gradient. It can be calculated by

$\chi_{i j}=e_{i t s} \eta_{j t s}$,

where $e_{\text {itc }}$ is the permutation tensor.

\subsection{Constitutive equation of bulge model}

Fig. 1 shows the model of hydraulic bulging testing. In [43], one element in the specimen is selected. The length and thickness of the element, before being bulged, are $\mathrm{d} \rho^{\prime}$ and $\mathrm{d} r^{\prime}$, respectively. $u$ is the displacement of the element. In the coordinate system $(\theta, \phi, r)$, the longitudinal strain $\varepsilon_{\theta}$ and the hoop strain $\varepsilon_{\phi}$ are expressed as follows

$\varepsilon_{\theta}=\ln \frac{\mathrm{d} \rho}{(\mathrm{d} \rho-\mathrm{d} u) \cos \theta} ;$

$\varepsilon_{\phi}=\ln \frac{\rho}{\rho-u}$,

where $\mathrm{d} \rho$ and $\mathrm{d} r$ are the length and thickness of the bulged element, respectively; $\rho$ is the distance between the axis and the element.

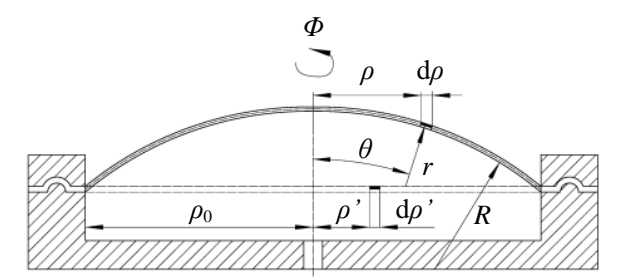

Fig. 1. Model of hydraulic Bulging test 
To determine the stress vs. strain curve, two assumptions are made as: (a) Volume is constant; (b) A hemisphere is formed during bulging. Under these two assumptions, a bulged sheet experiences equivalent biaxial strain at the polar of the dome. The strains could be calculated by the following equations:

$\varepsilon_{\phi}=\varepsilon_{\theta}$

$\varepsilon_{r}=-2 \varepsilon_{\theta}=-2 \varepsilon_{\phi}$,

where $\varepsilon_{r}$ is the strain in the $r$ direction.

$\ln \frac{\mathrm{d} \rho}{(\mathrm{d} \rho-\mathrm{d} u) \cos \theta}=\ln \frac{\rho}{\rho-u}$.

Substituting $\rho=r \sin \theta$ and $\mathrm{d} \rho=r \cos \theta \mathrm{d} \theta$ into Eq. (10),

$\frac{\mathrm{d} u}{\mathrm{~d} \theta}-\frac{u}{\sin \theta}=r(\cos \theta-1)$.

The displacement $u$ is obtained from Eq. 11:

$u=\frac{\sin \theta}{1+\cos \theta}(r \cos \theta+c)$,

where $c$ is a constant.

The boundary condition on the clamped edge is $u=0$, when $\rho=\rho_{0}$ and $r=R$, so the constant $c=-R \cos \theta_{0}$, in which $R$ is the radius of the specimen on the neutral surface.

$u=\frac{\sin \theta}{1+\cos \theta}\left(r \cos \theta-R \cos \theta_{0}\right)$.

Substituting Eq. 13 into Eq. 7:

$\varepsilon_{\theta}=\varepsilon_{\phi}=\ln \frac{\rho}{\rho-u}=\ln \frac{r(1+\cos \theta)}{r+R \cos \theta_{0}}$.

The longitudinal strain and the hoop strain could be simplified as

$\varepsilon_{\theta}=\varepsilon_{\varphi}=\ln \frac{r(1+\cos \theta)}{r+R \cos \theta_{0}}$.

Substituting Eq. 15 into Eq. 9:

$\varepsilon_{r}=-2 \varepsilon_{\theta}=-2 \ln \frac{r(1+\cos \theta)}{r+R \cos \theta_{0}}$.

Defining the coordinate system $(\theta, \phi, r)$ as coordinate system $(1,2,3)$, one can obtain

$\left[\varepsilon_{i j}\right]=\left[\begin{array}{ccc}A & 0 & 0 \\ 0 & A & 0 \\ 0 & 0 & -2 A\end{array}\right]$,

where $A=\ln \left[r(1+\cos \theta) /\left(r+R \cos \theta_{0}\right)\right]$.

The effective strain is

$\varepsilon_{\mathrm{e}}=2 \ln \frac{r(1+\cos \theta)}{r+R \cos \theta_{0}}$.
From Eq. 4, the calculation results of the strain gradient $\eta_{i j k}$ is

$\left[\eta_{i j k}\right]=\left[\left[\begin{array}{ccc}-C & 0 & 0 \\ 0 & -C & 0 \\ B & 0 & 2 C\end{array}\right]\left[\begin{array}{ccc}0 & -C & 0 \\ 0 & 0 & 0 \\ 0 & B & 0\end{array}\right]\left[\begin{array}{ccc}B & 0 & 2 C \\ 0 & B & 0 \\ 0 & 0 & -2 B\end{array}\right]\right]$,

where $B=R \cos \theta_{0} /\left[r\left(r+R \cos \theta_{0}\right)\right], C=\sin \theta /(1+\cos \theta)$.

The first deviatoric invariant of the strain gradient $\eta_{i j k}^{(1)}$ is:

$\left.\left[\eta_{i j k}^{\prime(1)}\right]=\left[\begin{array}{ccc}-\frac{4}{5} C & 0 & \frac{4}{5} B \\ 0 & -\frac{3}{5} C & 0 \\ \frac{4}{5} B & 0 & \frac{7}{5} C\end{array}\right]\left[\begin{array}{ccc}0 & -\frac{3}{5} C & 0 \\ -\frac{3}{5} C & 0 & \frac{4}{5} B \\ 0 & \frac{4}{5} B & 0\end{array}\right]\left[\begin{array}{ccc}\frac{4}{5} B & 0 & \frac{7}{5} C \\ 0 & \frac{4}{5} B & 0 \\ \frac{7}{5} C & 0 & -\frac{8}{5} B\end{array}\right]\right]$.

The rotational strain gradient $\chi_{i j}$ is computed by Eq. 5, and one can get

$\left[\chi_{i j}\right]=\left[\begin{array}{ccc}0 & -\frac{1}{2} B & 0 \\ \frac{1}{2} B & 0 & -C \\ 0 & -\frac{1}{2} C & 0\end{array}\right]$.

The effective rotational strain gradient, $\chi_{\mathrm{e}}$, is

$\chi_{\mathrm{e}}=\sqrt{\frac{2}{3} \chi_{i j} \chi_{i j}}=\sqrt{\frac{5}{6} C^{2}+\frac{1}{3} B^{2}}$.

The effective strain gradient, $\eta$, is

$\begin{aligned} \eta & =\left[\left(\frac{l_{1}}{l_{\mathrm{CS}}}\right)^{2} \eta_{i j k}^{(1)} \eta_{i j k}^{\prime(1)}+\chi_{\mathrm{e}}^{2}\right]^{1 / 2} \\ & =\left[\left(\frac{l_{1}}{l_{\mathrm{CS}}}\right)^{2}\left(\frac{38}{5} C^{2}+\frac{32}{5} B^{2}\right)+\left(\frac{5}{6} C^{2}+\frac{1}{3} B^{2}\right)\right]^{1 / 2}\end{aligned}$

In the Bulging test, the geometrical parameter $\beta=\sqrt{2 S_{0} / t}$, where $S_{0}$ is the area of the specimen before being bulged, $S_{0}=\pi \cdot \rho_{0}^{2} ; t$ is the thickness of the specimen before being bulged. Substituting Eq. 23 into Eq. 2, the constitutive relation used in the analytical model is obtained as

$$
\sigma_{\mathrm{e}}=K \varepsilon_{\mathrm{e}}^{n} \cdot\left[1+\frac{2 \pi \cdot \rho_{0}^{2}}{t} \cdot \frac{l_{1}^{2}\left(\frac{38}{5} C^{2}+\frac{32}{5} B^{2}\right)+l_{\mathrm{CS}}^{2}\left(\frac{5}{6} C^{2}+\frac{1}{3} B^{2}\right)}{\varepsilon_{\mathrm{e}}^{2}}\right] .
$$

\section{BULGING TEST}

To verify the constitute equation proposed in the former section, a series of bulging testing were conducted to investigate the effects of the sheet thickness and bulging radius on the material flow stress.

\subsection{Experimental setup}

Fig. 2 shows the experimental setup of the bulging test. The circle sample of the thin brass ( $35 \% \mathrm{Zn}$ ) sheet was located on the cavity mould and fixed by a blank holder. The 
punching ball was assembled under a force transducer, and then assembled totally to the middle beam of a CMT4104 type high precision material testing machine. The middle beam was driven by the screw rod of the machine and controlled by a computer. It pushed the punching ball to bulge the brass sheet sample until the crack happened on the surface of the sheet. During the bulging testing process, the displacement of the middle beam and the force measured by the force transducer were taken down ten times every second.

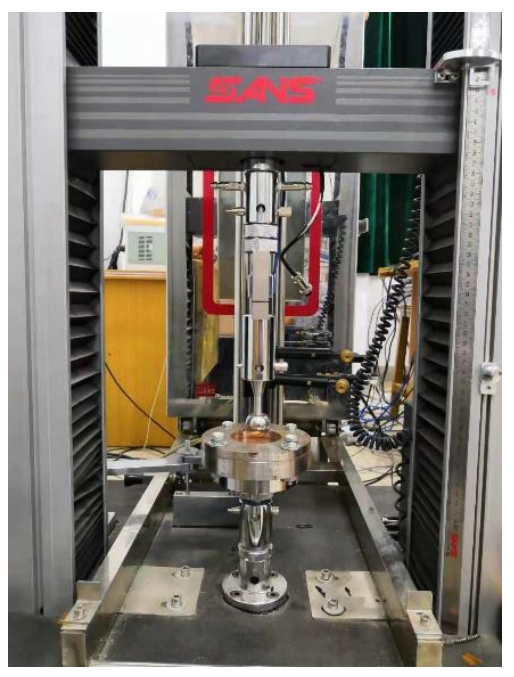

a

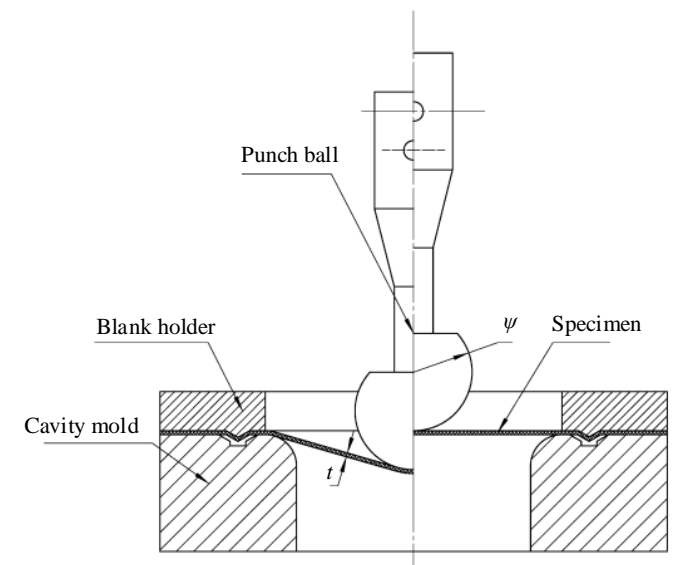

b

Fig. 2. Bulging test setup: $a$ - experiment setup; $b$ - bulging model

The accuracy of the force transducer was verified as $0.5 \%$. And the resolution of the displacement measuring device was $0.3 \mu \mathrm{m}$. The specifications of them were high enough to perform the test.

To investigating the size effect in Bulging test, as shown in Table 1, thin brass sheets with four different thicknesses were bulged by the four punching balls of different radiuses.

Table 1. The Bulging test parameters for the thin brass sheet

\begin{tabular}{|c|c|c|c|c|}
\hline & $\psi=15 \mathrm{~mm}$ & $\psi=5 \mathrm{~mm}$ & $\psi=2.5 \mathrm{~mm}$ & $\psi=1.5 \mathrm{~mm}$ \\
\hline$t=300 \mu \mathrm{m}$ & $\sqrt{ }$ & - & - & - \\
\hline$t=100 \mu \mathrm{m}$ & $\sqrt{ }$ & $\sqrt{ }$ & - & - \\
\hline$t=50 \mu \mathrm{m}$ & $\sqrt{ }$ & $\sqrt{ }$ & $\sqrt{ }$ & - \\
\hline$t=30 \mu \mathrm{m}$ & $\sqrt{ }$ & $\sqrt{ }$ & $\sqrt{ }$ & $\sqrt{ }$ \\
\hline
\end{tabular}

\subsection{Material preparation}

Before being cut into the circle specimen, the brass sheets of the four different thicknesses were annealed at the same $550{ }^{\circ} \mathrm{C}$ for 120 minutes in the Nitrogen atmosphere in order to eliminate the effects of rolling texture and residual stress. The heat-treated brass sheets were made into two types of metallographic specimens. One was prepared to observe the grain distributed on the section (see Fig. 3), while another one was for that on the plate (see Fig. 4). From the cross-section of the samples, as shown in Fig. 3, the average size of them was about were about $(20 \sim 25) \mu \mathrm{m}$. There were only 1 to 2 grains on the cross of the $30 \mu \mathrm{m}$ sheet, and 2 to 3 grains on that of the $50 \mu \mathrm{m}$ sheet. The size of the grain from the view on the plate, as shown in Fig. 4, was about $(25 \sim 30) \mu \mathrm{m}$.

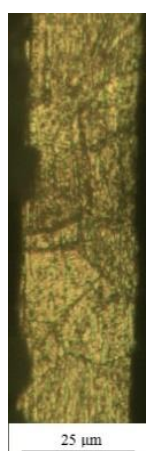

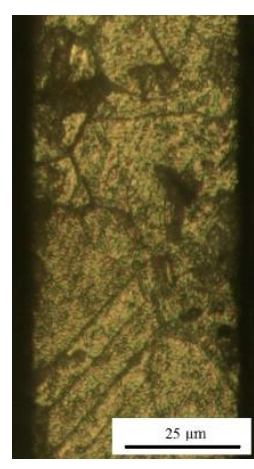

b
Fig. 3. The metallograph of the annealed brass sheet with various thicknesses, on the cross section: $\mathrm{a}-30 \mu \mathrm{m} ; \mathrm{b}-50 \mu \mathrm{m}$

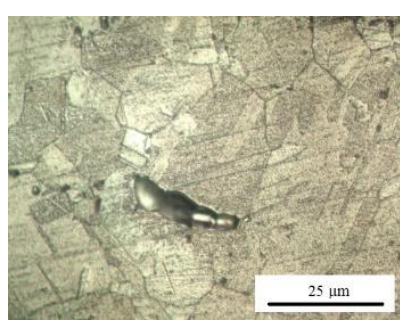

a

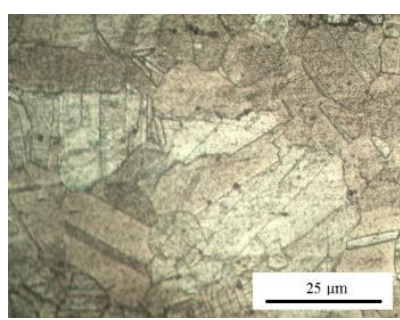

c

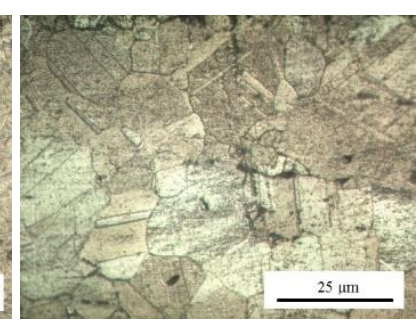

b

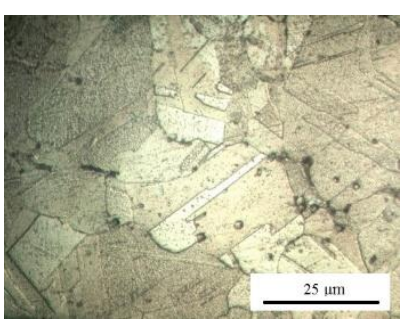

d
Fig. 4. Metallograph of the annealed brass sheet with various thicknesses, on the plate: $\mathrm{a}-.30 \mu \mathrm{m} ; \mathrm{b}-50 \mu \mathrm{m} ; \mathrm{c}-100$ $\mu \mathrm{m} ; \mathrm{d}-300 \mu \mathrm{m}$

\subsection{Data processing}

Fig. 5 shows the deformed sample being bulged by the punching ball. From the figure, the geometric relationship is obtained,

$\left(h-\left(\psi-\sqrt{\psi^{2}-D^{2}}\right)\right) /(\Theta-D)=D / \sqrt{\psi^{2}-D^{2}}$, 
where $h$ is the bulge depth; $\psi$ is the radius of punching ball; $D$ is the radius of the boundary ring of the contact area between the ball and sheet; $\Theta$ is the radius of the die. It is deduced from Eq. 25:

$(h-\psi) \sqrt{\psi^{2}-D^{2}}=\Theta \cdot D-\psi^{2}$.

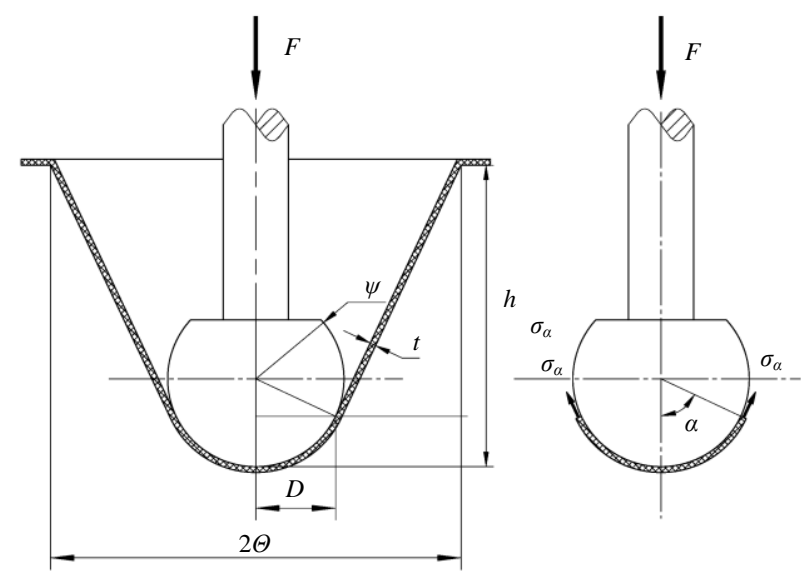

Fig. 5. Schematic diagram of metal sheet bulged

Because of $\sqrt{\psi^{2}-D^{2}} \geq 0$,

$\left\{\begin{array}{l}D \geq \frac{\psi^{2}}{\Theta},(h \geq \psi) \\ D<\frac{\psi^{2}}{\Theta},(h<\psi)\end{array}\right.$.

Eq. 26 can be transferred into

$\left[\Theta^{2}+(h-\psi)^{2}\right] D^{2}-2 \Theta D \psi^{2}+h \psi^{2}(2 \psi-h)=0$.

So $D$ could be obtained from the Eq. 28 as:

$D=\frac{\Theta \psi^{2} \pm \psi \sqrt{\Theta^{2} \psi^{2}-\left(2 \psi h-h^{2}\right) \cdot\left[\Theta^{2}+(h-\psi)^{2}\right]}}{\Theta^{2}+(h-\psi)^{2}}$.

From Eq. 27, it can get that

$D=\left\{\begin{array}{l}\frac{\Theta \psi^{2}+\psi \sqrt{\Theta^{2} \psi^{2}-\left(2 \psi h-h^{2}\right) \cdot\left[\Theta^{2}+(h-\psi)^{2}\right]}}{\Theta^{2}+(h-\psi)^{2}},(h \geq \psi) \\ \frac{\Theta \psi^{2}-\psi \sqrt{\Theta^{2} \psi^{2}-\left(2 \psi h-h^{2}\right) \cdot\left[\Theta^{2}+(h-\psi)^{2}\right]}}{\Theta^{2}+(h-\psi)^{2}},(h<\psi) .\end{array}\right.$

As shown in Fig. 5, the equation of equilibrium for the spherical cap in the axial direction is

$2 D \pi t \cdot \sigma_{\alpha} \cdot \sin \alpha-F=0$.

From the geometric relationship, it could be obtained that

$\sin \alpha=\frac{D}{\psi}$.

Substituting Eq. 32 into Eq. 31

$\sigma_{\alpha}=\frac{F \cdot \psi}{2 \pi t D^{2}}$.
The tensile stress in the tangential direction is obtained by substituting Eq. 30 into Eq. 33:

$\sigma_{\alpha}=\left\{\begin{array}{c}\frac{F \cdot \psi\left[\Theta^{2}+(h-\psi)^{2}\right]^{2}}{2 \pi t\left\{\Theta \psi^{2}+\psi \sqrt{\Theta^{2} \psi^{2}-\left(2 \psi h-h^{2}\right) \cdot\left[\Theta^{2}+(h-\psi)^{2}\right]}\right\}^{2}},(h \geq \psi) \\ \frac{F \cdot \psi\left[\Theta^{2}+(h-\psi)^{2}\right]^{2}}{2 \pi t\left\{\Theta \psi^{2}-\psi \sqrt{\Theta^{2} \psi^{2}-\left(2 \psi h-h^{2}\right) \cdot\left[\Theta^{2}+(h-\psi)^{2}\right]}\right\}^{2}},(h<\psi)\end{array}\right.$

$\sigma_{\alpha}$ is calculated by substituting the punch force $F$ and bulging depth $h$, which were recorded during the bulging experiment, into Eq. 34.

\section{FINITE ELEMENT ANALYSIS}

Using the constitute equation considering the SGH, finite element analysis of the bulging test was carried out.

\subsection{Finite element analysis model}

The FE simulation was performed by the commercial code ABAQUS. Fig. 6 shows the finite element analysis model of the bugle testing. The cavity model and the punching ball were set as analytically rigid body. Because it is an axisymmetric model, a quarter of the specimen was modelled and meshed by the 8-node linear brick element, C3D8. As shown in Fig. 6 b, the elements in the centre area of the specimen are fined.

The boundary on the circle of the specimen was fixed totally. The friction between the ball and the sheet was computed by the penalty function method with the friction factor of 0.2 . The load applied to the sheet was controlled by displacement of the punching ball.

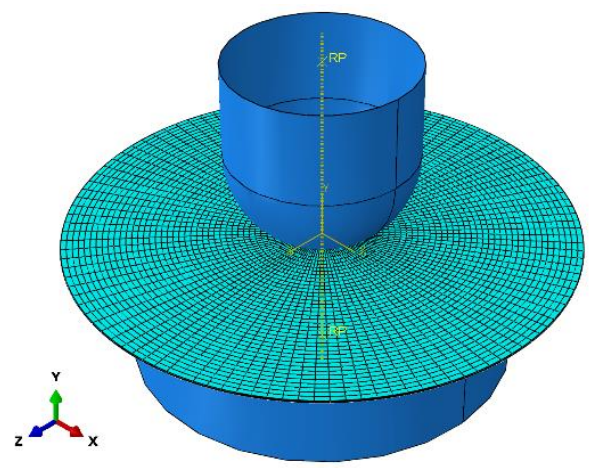

Fig. 6. Finite element analysis model

\subsection{Constitutive model}

The bulging testing process was simulated by ABAQUS/Standard using the constitutive equation, Eq. 24, which considering the strain and the SGH. A constitutive subroutine UMAT of the special constitute equation was developed. Fig. 7 shows the flow chart of the UMAT program. On each Gauss point, not only the strain but also the strain gradient was calculated. The strain gradient was computed by the Eq. (24). To compare with the simulation results considering the $\mathrm{SGH}$, the same finite element model but using the classical plasticity theory was also computed. 
In the former study [44], uniaxial tension of the same brass thin sheet had been carried out. $K$ and $n$ were chosen as $811 \mathrm{MPa}$ and 0.34 , respectively.

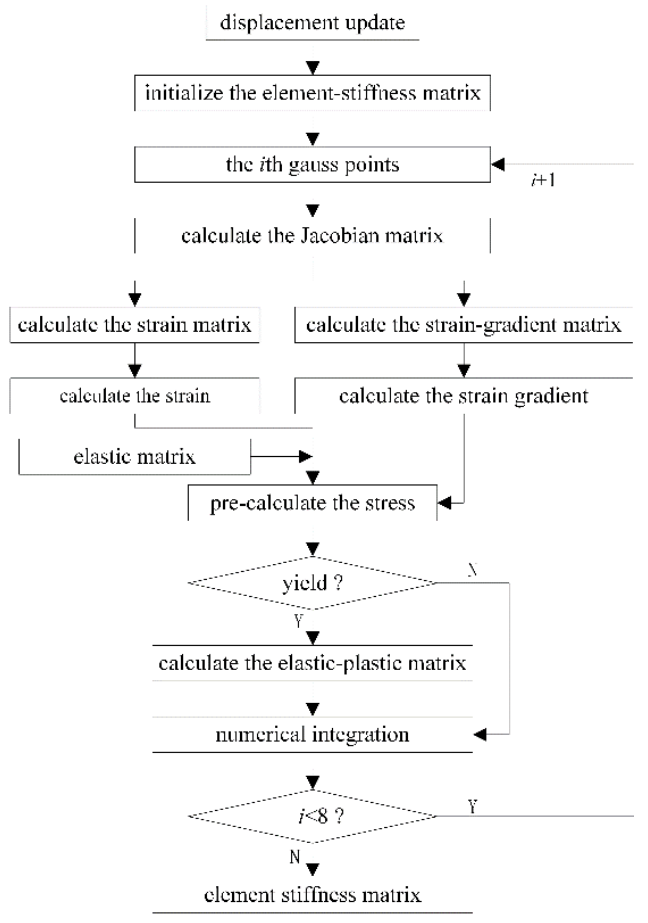

Fig. 7. Flow chart of the UMAT program

\section{RESULTS AND DISCUSSION}

The bulged samples were shown in Fig. 8. The punch force $F$ and bulging depth $h$ recorded during the bulging testing were substituted into Eq. 34 to calculate the tangential-direction tensile stress $\sigma_{\alpha}$, as shown in Fig. 5.

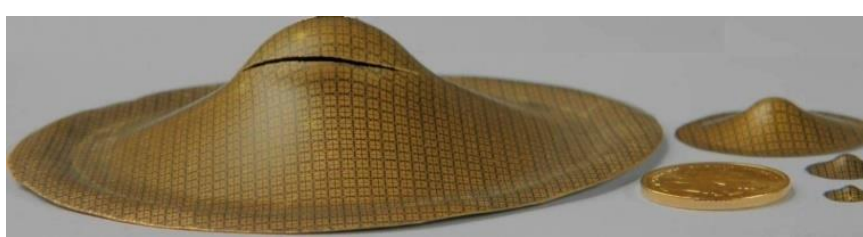

Fig. 8. Bulged samples of brass sheet with different thicknesses and bulge radiuses

\subsection{Effects of strain on the tangential-direction tensile stress}

Fig. 9 shows the experimental results of the tangentialdirection tensile stress, $\sigma_{\alpha}$, of the four specimens with the same ratio of the sheet thickness to punching ball radius. The ratio indicated the size characteristic of the bulging testing. Table 2 lists the detail data in Fig. 9 a. It was obviously that $\sigma_{\alpha}$ decreased with the increment of the ratio of bulging depth to the punching ball radius, $h / \psi$, which represented the bulging processing and was related to the deformation of the thin sheet. This argument could be reinforced by the observed phenomenon in the reported literature that the flow stress decreased with the increment of strain [19].

However, according to the classical plasticity theory, the strain and stress would increase with the thin sheet was bulged more and more deeply, as the FEA results shown in Fig. 9.

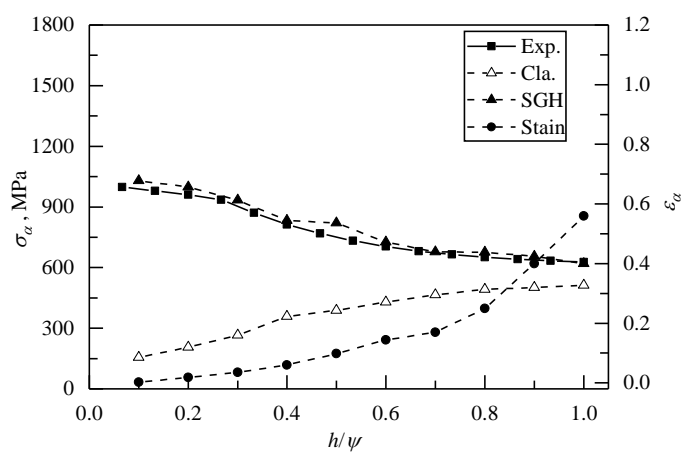

a

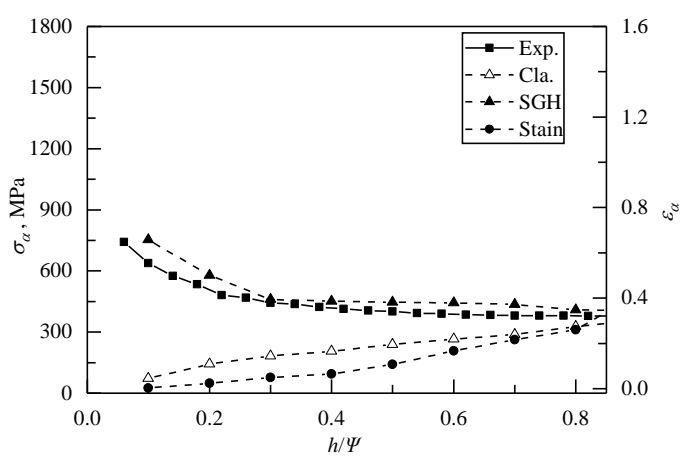

b

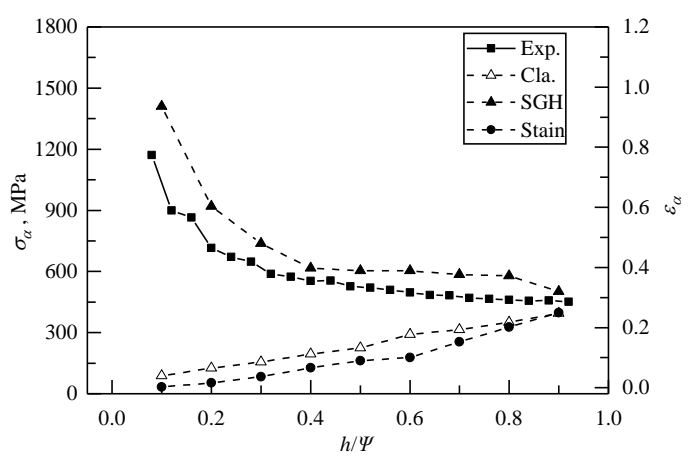

c

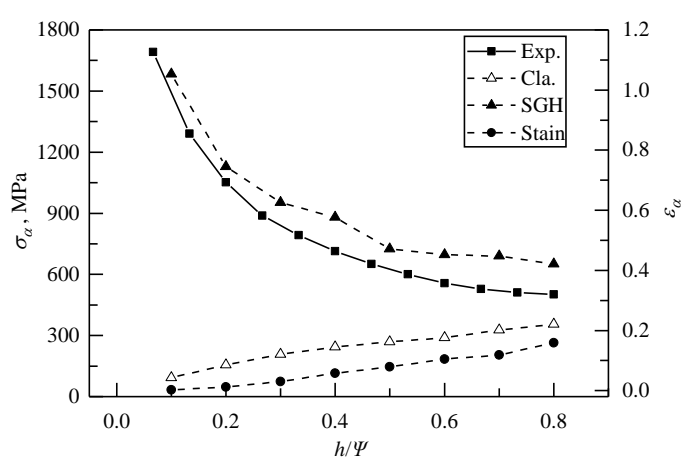

d

Fig. 9. Comparison of the stresses from the experiment (Exp.) with the simulation based on the strain gradient hardening $(\mathrm{SGH})$ and classical plasticity theory (Cla.), for various thicknesses and punching ball radius: $\mathrm{a}-t=300 \mu \mathrm{m}$, $\Psi=15 \mathrm{~mm} ; \quad \mathrm{b}-t=100 \mu \mathrm{m}, \quad \Psi=5 \mathrm{~mm} ; \quad \mathrm{c}-t=50 \mu \mathrm{m}$, $\Psi=2.5 \mathrm{~mm} ; \mathrm{d}-t=30 \mu \mathrm{m}, \Psi=1.5 \mathrm{~mm}$ 
It seems that the classical plasticity was invalid any more. The SGH played an important role in the Bulging test. Based on the proposed constitute equation, into which the SGH factor, $\left(2 \pi \cdot D^{2}\right)\left(l^{2} \eta^{2}\right) /\left(t \cdot \varepsilon_{\mathrm{e}}^{2}\right)$, was introduced, the FEA results of $\sigma_{\alpha}$ agreed with those from the experiment. The trend of stress could be captured.

The deviation of the stresses, got from the classical plasticity theory and the developed SGH law, became smaller and smaller as the strain increased. It was indicated that the function of the SGH was dependent on the strain. However, the relationship would be weaker with the increment of the strain. It also could be inferred from the SGH factor that the effect would diminish with the strain the continuous increment of strain.

Table 2. Comparison of the stresses from the experiment (Exp.) with the simulation based on the strain gradient hardening (SGH) and classical plasticity theory (Cla.), for various thicknesses and punching ball radius

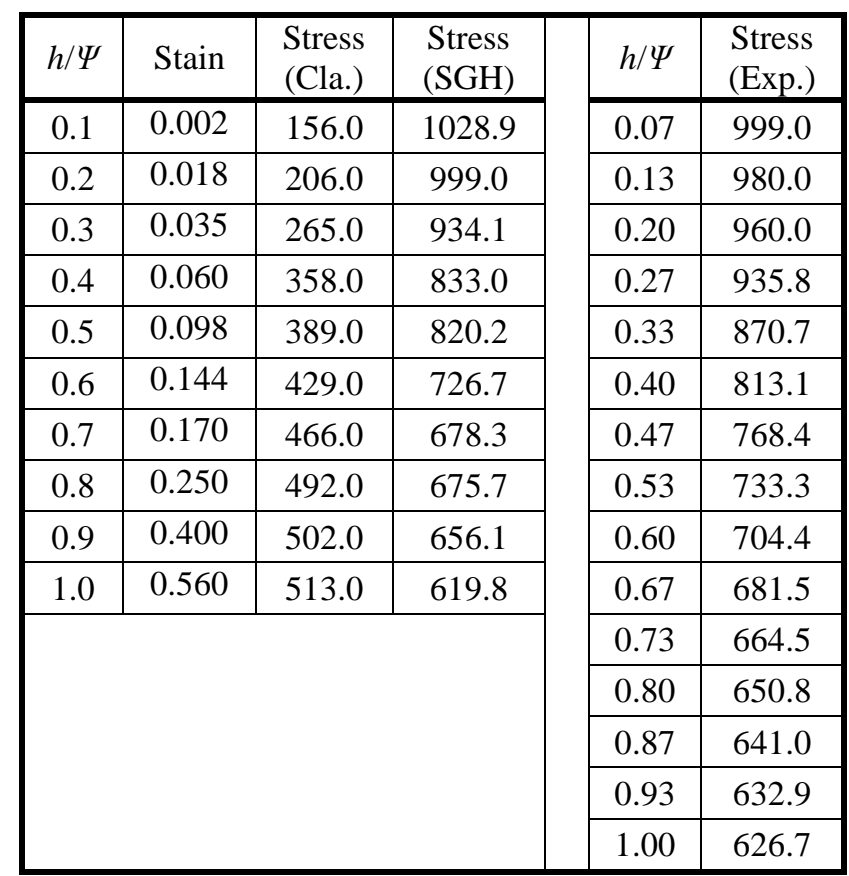

\subsection{Effects of the sheet thickness on the tangential-} direction tensile stress

The experiment results of the thin sheets of different thicknesses bulged by the punching balls with radiuses of $15 \mathrm{~mm}$ and $5 \mathrm{~mm}$ were shown in Fig. 10 and Fig. 11, respectively.

It can be seen from Fig. $10 \mathrm{a}$ and Fig. $10 \mathrm{~b}$ that the tangential stress decreased as the thickness of the thin plate reduced from $300 \mu \mathrm{m}$ to $100 \mu \mathrm{m}$. In the study of [45], the size effect was classified into first order and second order based on the thickness of the thin plate. The transforming thickness was about $10 l$, in which $l$ is the material intrinsic length [28, 42]. The transforming thickness of the brass was about $60 \mu \mathrm{m}$ because its material intrinsic length was $6 \mu \mathrm{m}$ $[32,46]$. When the thickness was larger than $60 \mu \mathrm{m}$, the flow stress decreased during the decrement of the thickness. This phenomenon of stress reduction was called the first order size effect [47].

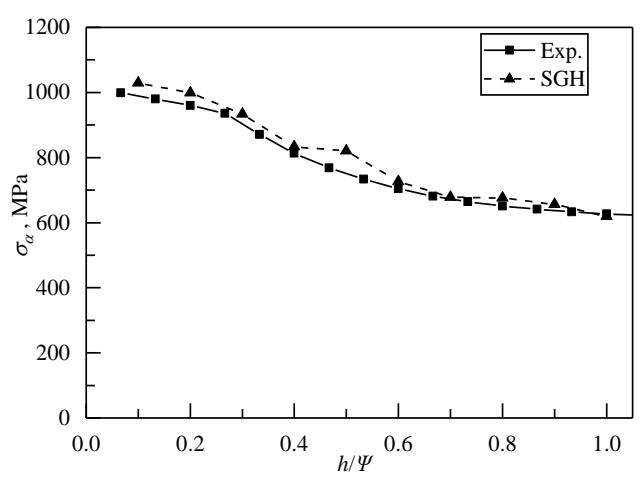

a

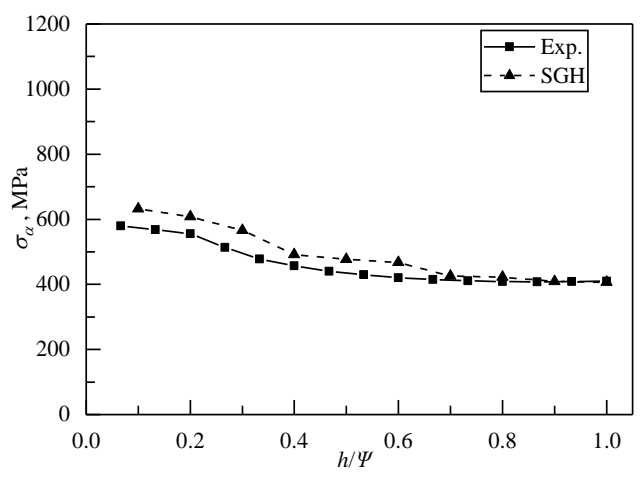

b

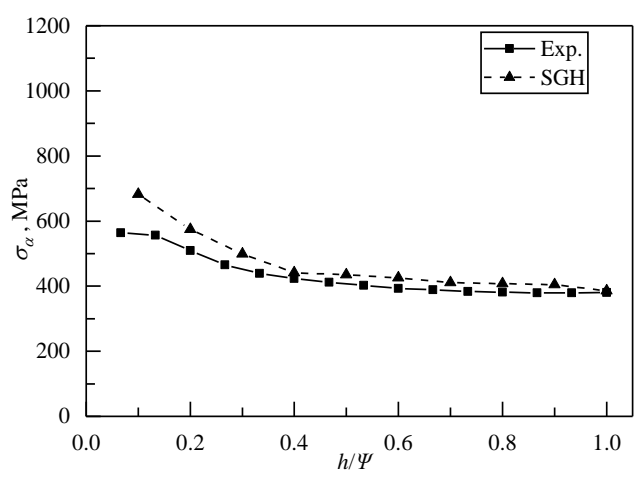

c

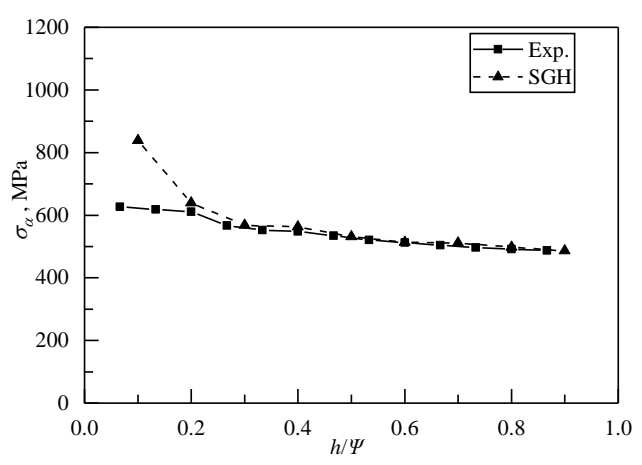

d

Fig. 10. Comparison of the stresses from the experiment (Exp.) with the simulation based on the strain gradient hardening (SGH), for various sheet-thicknesses and $\Psi=15 \mathrm{~mm}$ : $\mathrm{a}-t=300 \mu \mathrm{m} ; \quad \mathrm{b}-t=100 \mu \mathrm{m} ; \quad \mathrm{c}-t=50 \mu \mathrm{m} ;$ $\mathrm{d}-t=30 \mu \mathrm{m}$ 


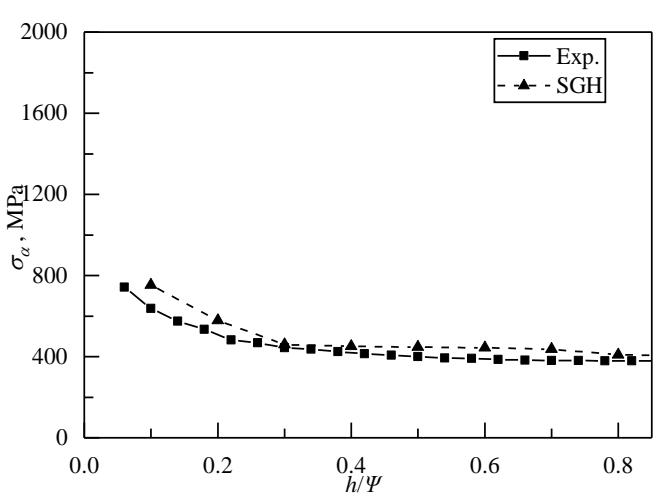

a

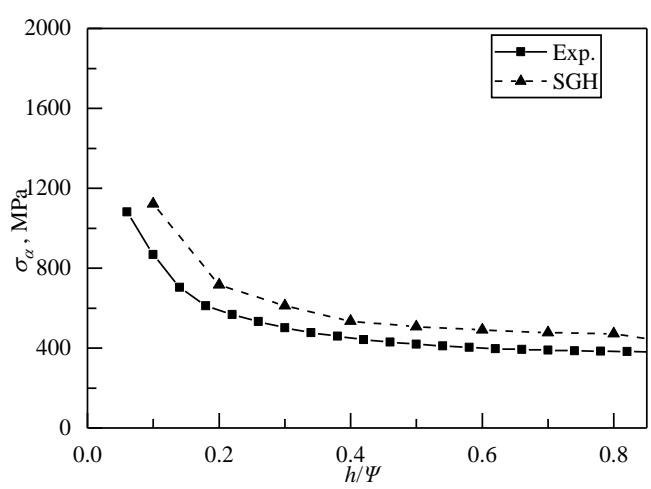

b

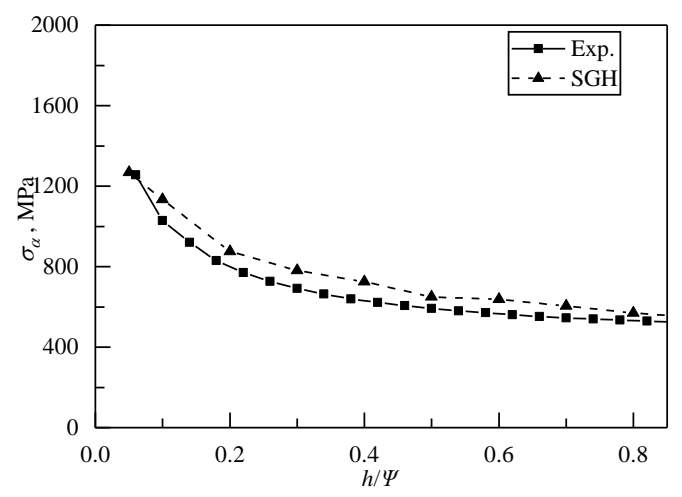

c

Fig. 11. Comparison of the stresses from the experiment (Exp.) with the simulation based on the strain gradient hardening (SGH), for various sheet-thicknesses and $\Psi=5 \mathrm{~mm}$ : $\mathrm{a}-t=100 \mu \mathrm{m} ; \mathrm{b}-t=50 \mu \mathrm{m} ; \mathrm{c}-t=30 \mu \mathrm{m}$

The reduction in tangential stress was due to a decrease in statistical storage dislocation density within the sheet as the thickness of the sheet decreased. From the surface layer model [48-50], when the thickness of the thin plate was continuously reduced, the proportion of free grains on the surface of the cross section of the plate was increasing. Because the constraining force of the free grain on the surface was much smaller than that of the internal grain, the dislocation could not be deposited on the surface layer. In that case, the hardening effect of the dislocation was eliminated as the thin sheet thickness reduced. It could be proved that the first order size effect was directly related to the statistical storage dislocation density.

The tangential stress in Fig. $10 \mathrm{c}$ and Fig. $10 \mathrm{~d}$ show inverse phenomenon. It increased as the increment of the thickness, which was called the second order size effect [51]. The phenomenon was caused by the SGH effect. When the plate thickness was smaller than $60 \mu \mathrm{m}$, there were only a few numbers of grains on the cross-section. The inhomogeneous deformation of the grains would be induced during the bulging process, in which case, the geometrically necessary dislocations were generated. In the study of Ref. $[28,42]$, the flow stress hardening was related to the geometrically necessary dislocations. So, the SGH should be introduced in the study of the bulging of the thin brass sheet below $60 \mu \mathrm{m}$.

According to Eq. 24, which was proposed in this paper, the stain gradient was considered in the constitutive equation. It is shown that the thickness $t$ was an inverse proportion to the SGH factor, $\left(2 \pi \cdot D^{2}\right)\left(l^{2} \eta^{2}\right) /\left(t \cdot \varepsilon_{\mathrm{e}}^{2}\right)$. The hardening effect of the strain gradient was related to the thickness of the thin sheet. When the thickness was not smaller enough, the hardening effect was not obvious. The finite element simulation, which was carried out based on the constitutive equation considering the SGH, could capture the stress variation tendency. While the simulation results of the stress calculated by the conventional theory of plasticity showed a larger deviation, comparing to the stress results got from the bulging experiment. The same results also could be observed from the thin sheets bulged by the ball with a radius of $5 \mathrm{~mm}$, as shown in Fig. 11 .

\subsection{Effects of the punching ball radius on the tangential-direction tensile stress}

As shown in Fig. 12 and Fig. 13, the tangential stress increased as the radius of punching ball reduced. From the analysis result, it was supposed that the SGH was caused by the inhomogeneous deformation of the grains. It could be inferred that the inhomogeneous deformation was not only related to the thickness but also the radius of the bulging ball. As the radius of the punching ball decreased, the curvature of the thin sheet of the same thickness increased during the bulging process. In that situation, more geometrically necessary dislocations were required to coordinate the increasing non-uniform deformation. Therefore, the SGH was enhanced, and the tangential stress increased as the radius of the ball decreased. Similar experiment results were also observed in the bulging test that the stress increased when bulging diameter was reduced [19].

From the experiment results, it was found that the decrement of the radius of the punching ball would enhance the SGH during the thin sheet bulging process.

\section{CONCLUSIONS}

In the study, the stresses of the thin sheets with thicknesses from $300 \mu \mathrm{m}$ to $30 \mu \mathrm{m}$ in the bulging test were discussed. A constitutive equation considering the SGH was proposed to investigate the size effect of the thin sheet. Finite element simulation and experiment were performed to verify the proposed constitutive equation. Conclusions could be drawn as follow.

In bulging test of thin brass sheet, the stress was sensitive to the thickness of the sheet and the radius of the punching ball. 


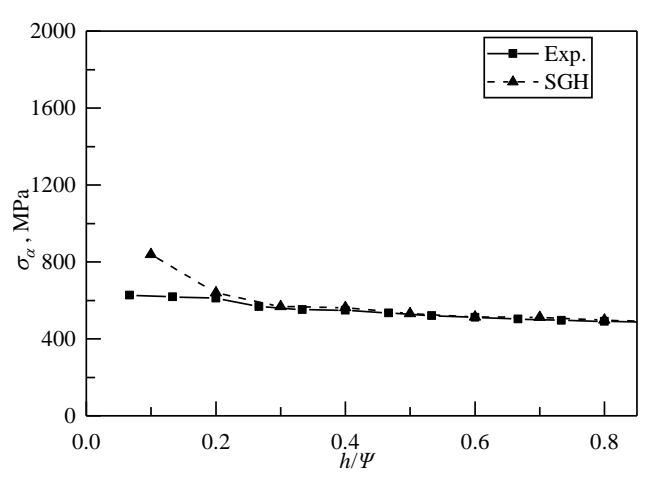

a

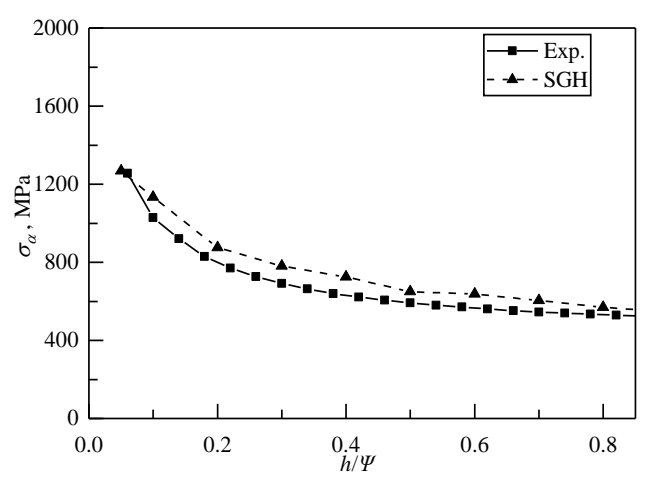

b

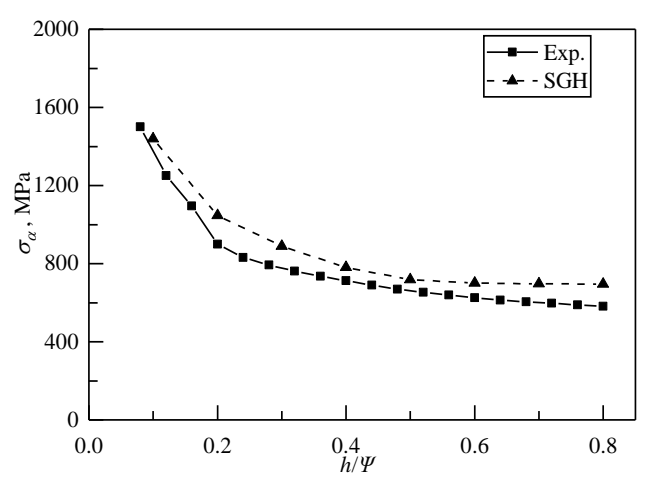

$\mathrm{c}$

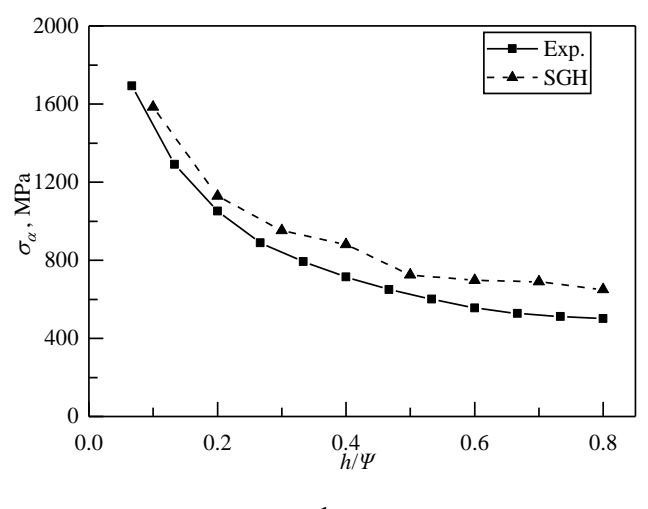

d

Fig. 12. Comparison of the stresses from the experiment (Exp.) with the simulation based on the strain gradient hardening (SGH), for various radiuses of punching ball and $t=30 \mu \mathrm{m}: \mathrm{a}-\Psi=15 \mathrm{~mm} ; \mathrm{b}-\Psi=5 \mathrm{~mm} ; \mathrm{c}-\Psi=2.5 \mathrm{~mm}$; $\mathrm{d}-\Psi=1.5 \mathrm{~mm}$

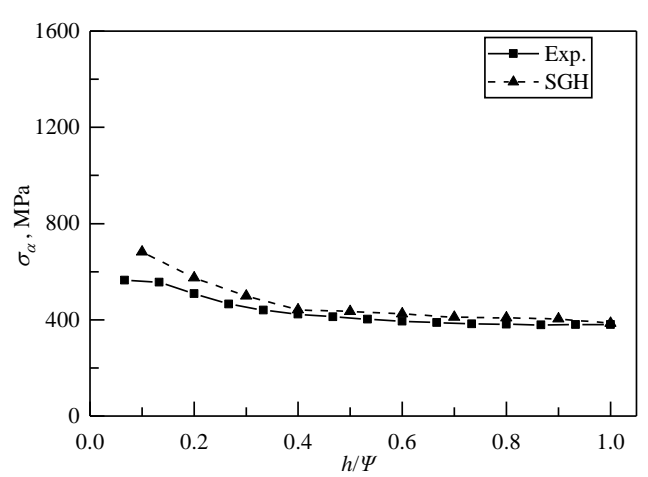

(a)

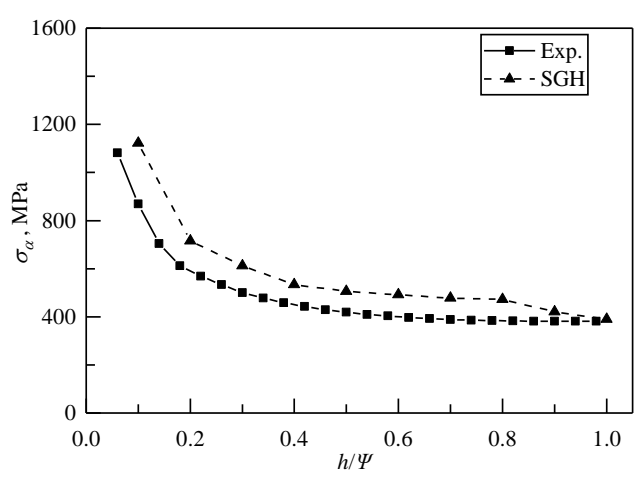

(b)

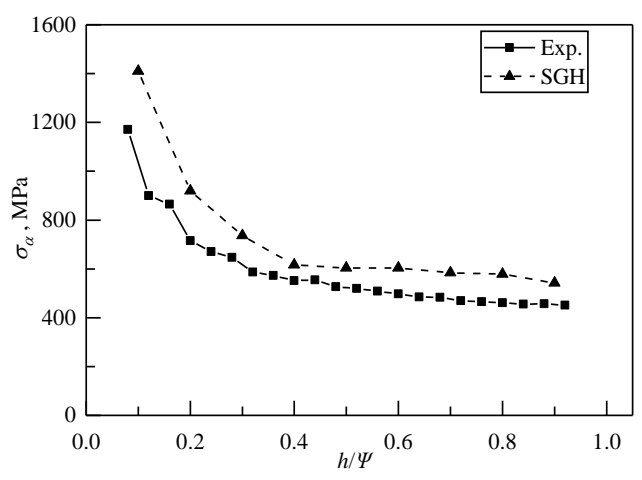

(c)

Fig. 13. Comparison of the stresses from the experiment (Exp.) with the simulation based on the strain gradient hardening (SGH), for various radiuses of punching ball and $t=50 \mu \mathrm{m}: \mathrm{a}-\Psi=15 \mathrm{~mm} ; \mathrm{b}-\Psi=5 \mathrm{~mm} ; \mathrm{c}-\Psi=2.5 \mathrm{~mm}$

When the thickness reduced to the level of 10 times of the material intrinsic length, the inhomogeneous deformation of the grains would cause the generation of the geometrically necessary dislocations, which induced the SGH during the bulging test. Besides that, the decrement of the punching ball radius would also increase the inhomogeneous deformation and enhance the SGH during the thin sheet bulging process.

The SGH during the thin sheet bulging test was related to the strain of the sheet. The hardening effect of the strain gradient was obvious when the strain was small. The constitutive equation which was used in the calculation of the stress in the simulation could capture the stress variations. While the results of the simulation based on the conventional theory of plasticity showed a large deviation from the experiment results. 
The SGH should be considered in the thin sheet bulging test with the second order size effect.

\section{REFERENCES}

1. Ma, Z., Cao, Z., Lu, J., Li, H., Zhang, Y., Liu, W., Yin, Z. Material Flow Behavior Modeling with Consideration of Size Effects Rare Metals 37 (11) 2018: pp. 995-1002. http://dx.doi.org/10.1007/s12598-018-1156-1.

2. Yin, P., Zhang, S., Qi, Y., Xin, J. Quantization and Training of Low Bit-Width Convolutional Neural Networks for Object Detection Journal of Computational Mathematics 37 (3) 2019: pp. 349-360. http://dx.doi.org/10.4208/jcm.1803-m2017-0301.

3. Sahu, J., Chakrabarty, S., Raghavan, R., Mishra, S. Investigations of Size Effect on Formability and Microstructure Evolution in Ss304 Thin Foils Journal of Strain Analysis for Engineering Design $53(7)$ 2018: pp. $517-528$. http://dx.doi.org/10.1177/0309324718792443.

4. Wang, H., Rui, H., Zhang, S. An Optimal-Order Error Estimate for the Mass-Conservative Characteristic Finite Element Scheme Applied Mathematics and Computation 218 (20) 2012: pp. $10271-10278$. http://dx.doi.org/10.1016/j.amc.2012.04.004.

5. Zhang, S., Yin, P., Xin, J. Transformed Schatten-1 Iterative Thresholding Algorithms for Low Rank Matrix Completion Communications in Mathematical Sciences 15(3) 2017: pp. 839-862. http://dx.doi.org/10.4310/CMS.2017.v15.n3.a12.

6. Engel, U., Eckstein, R. Microforming - From Basic Research to its Realization Journal of Materials Processing Technology 125-126 2002: pp. 35-44. http://dx.doi.org/10.1016/S0924-0136(02)00415-6.

7. Fu, M., Chan, W. A Review On the State-of-the-Art Microforming Technologies International Journal of Advanced Manufacturing Technology 2013: pp. 2411-2437. http://dx.doi.org/10.1007/s00170-012-4661-7.

8. Vollertsen, F., Niehoff, H., Hu, Z., Theiler, C. State of the Art in Micro Forming and Investigations Into Micro Deep Drawing Journal of Materials Processing Technology 2004: pp. $70-79$.

http://dx.doi.org/10.1016/j.jmatprotec.2004.04.266

9. Engel, U., Egerer, E. Basic Research On Cold and Warm Forging of Microparts Key Engineering Materials 233-236 2003: pp. $449-456$. http://dx.doi.org/10.4028/www.scientific.net/KEM.233236.449 .

10. Chen, W., Kitamura, T., Wang, X., Feng, M. Size Effect on Cyclic Torsion of Micro-Polycrystalline Copper Considering Geometrically Necessary Dislocation and Strain Gradient International Journal of Fatigue 117 2018: pp. 292-298. http://dx.doi.org/10.1016/j.ijfatigue.2018.08.027.

11. Zhang, K.F., Kun, L. Classification of Size Effects and Similarity Evaluating Method in Micro Forming Journal of Materials Processing Technology 209 (11) 2009: pp. $4949-4953$.

http://dx.doi.org/10.1016/j.jmatprotec.2008.11.018

12. Tamai, Y., Inazumi, T., Manabe, K. Fe Forming Analysis with Nonlinear Friction Coefficient Model Considering Contact Pressure, Sliding Velocity and Sliding Length Journal of Materials Processing Technology 227 2016: pp. $161-168$. http://dx.doi.org/10.1016/j.jmatprotec.2015.08.023.
13. Tanaka, T., Hirata, T., Shinomiya, N., Shirakawa, N. Analysis of Material Flow in the Sheet Forming of FrictionStir Welds On Alloys of Mild Steel and Aluminum Journal of Materials Processing Technology 226 2015: pp. $115-124$. http://dx.doi.org/10.1016/j.jmatprotec.2015.06.030.

14. Anand, D., Kumar, D.R. Effect of Thickness and Grain Size On Flow Stress of Very Thin Brass Sheets Procedia Materials Science 6 2014: pp. 154-160. http://dx.doi.org/10.1016/j.mspro.2014.07.019.

15. Mahabunphachai, S., Ko, M. Investigation of Size Effects On Material Behavior of Thin Sheet Metals Using Hydraulic Bulge Testing at Micro/Meso-Scales International Journal of Machine Tools and Manufacture 48 (9) 2008: pp. 1014-1029. http://dx.doi.org/10.1016/j.ijmachtools.2008.01.006.

16. Michel, J.F., Picart, P. Size Effects On the Constitutive Behaviour for Brass in Sheet Metal Forming Journal of Materials Processing Technology 141 (3) 2003: pp. $439-446$. https://doi.org/10.1016/S0924-0136(03)00570-3

17. Kals, T.A., Eckstein, R. Miniaturization in Sheet Metal Working Journal of Materials Processing Technology 103 (1) 2000: pp. 95-101. http://dx.doi.org/10.1016/S0924-0136(00)00391-5

18. Raulea, L.V., Goijaerts, A.M., Govaert, L.E., Baaijens, F.P.T. Size Effects in the Processing of Thin Metal Sheets Journal of Materials Processing Technology 115 (1) 2001: pp. 44-48. http://dx.doi.org/10.1016/S0924-0136(01)00770-1.

19. Diehl, A., Staud, D., Engel, U. Investigation of the Mechanical Behaviour of Thin Metal Sheets Using the Hydraulic Bulge Test, in: 4th International Conference on Multi-Material Micro Manufacture, Cardiff, Wales, UK, 2008: pp. 195-198.

20. Geiger, M., Vollertsen, F., Kals, R. Fundamentals On the Manufacturing of Sheet Metal Microparts Cirp Annals Manufacturing Technology 45 (1) 1996: pp. 277-282. http://dx.doi.org/10.1016/s0007-8506(07)63063-7

21. Lederer, M., Gröger, V., Khatibi, G., Weiss, B. Size Dependency of Mechanical Properties of High Purity Aluminium Foils Materials Science and Engineering: A 527 (3) 2010: pp. 590-599. http://dx.doi.org/http://dx.doi.org/10.1016/j.msea.2009.08.016.

22. Ashby, M.F. The Deformation of Plastically NonHomogeneous Materials Philosophical Magazine 21 1970: pp. $399-424$. http://dx.doi.org/10.1080/14786437008238426.

23. Ashby, M. The Deformation of Plastically NonHomogeneous Materials Philosophical Magazine 2006: pp. 399-424. http://dx.doi.org/10.1080/14786437008238426

24. Fleck, N.A., Muller, G.M., Ashby, M.F., Hutchinson, J.W. Strain Gradient Plasticity: Theory and Experiment Acta Metallurgica et Materialia 42 (2) 1994: pp. 475-487. http://dx.doi.org/10.1016/0956-7151(94)90502-9

25. Fleck, N.A., Hutchinson, J.W. A Phenomenological Theory for Strain Gradient Effects in Plasticity Journal of the Mechanics and Physics of Solids 41 (12) 1993: pp. $1825-1857$. http://dx.doi.org/10.1016/0022-5096(93)90072-N

26. Fleck, N.A., Hutchinson, J.W. Strain Gradient Plasticity Advances Applied Mechanics 33 1997: pp. 295-361. 
27. Hutchinson, J.W. Plasticity at the Micron Scale International Journal of Solids and Structures 37 (1) 2000: pp. $225-238$. http://dx.doi.org/10.1016/S0020-7683(99)00090-6

28. Fleck, N.A., Hutchinson, J.W. A Reformulation of Strain Gradient Plasticity Journal of the Mechanics and Physics of Solids 49 (10) 2001: pp. 2245-2271. http://dx.doi.org/10.1016/s0022-5096(01)00049-7

29. Engelen, R.A.B., $\quad$ Fleck, N.A., $\quad$ Peerlings, R.H.J., Geers, M.G.D. An Evaluation of Higher-Order Plasticity Theories for Predicting Size Effects and Localisation International Journal of Solids and Structures 43 (7-8) 2006: pp. $1857-1877$.

http://dx.doi.org/10.1016/j.ijsolstr.2004.05.072

30. Idiart, M.I., Deshpande, V.S., Fleck, N.A., Willis, J.R. Size Effects in the Bending of Thin Foils International Journal of Engineering Science 47 (11-12) 2009: pp. 1251-1264. http://dx.doi.org/10.1016/j.ijengsci.2009.06.002

31. Fleck, N.A., Willis, J.R. A Mathematical Basis for StrainGradient Plasticity Theory-Part I: Scalar Plastic Multiplier Journal of the Mechanics and Physics of Solids 57 (1) 2009: pp. $161-177$.

http://dx.doi.org/10.1016/j.jmps.2008.09.010

32. Fleck, N.A., Willis, J.R. A Mathematical Basis for StrainGradient Plasticity Theory. Part II: Tensorial Plastic Multiplier Journal of the Mechanics and Physics of Solids 57 (7) 2009: pp. $1045-1057$. http://dx.doi.org/10.1016/j.jmps.2009.03.007

33. Chen, S.H., Wang, T.C. A New Hardening Law for Strain Gradient Plasticity Acta Materialia 48 (16) 2000: pp. 3997-4005. http://dx.doi.org/10.1016/S1359-6454(00)00216-0.

34. Chen, S.H., Wang, T.C. New Hardening Law for Strain Gradient Plasticity Acta Materialia 48 (16) 2000: pp. 3997-4005. http://dx.doi.org/10.1016/s1359-6454(00)00216-0

35. Chen, S.H., Wang, T.C. Finite Element Solutions for Plane Strain Mode I Crack with Strain Gradient Effects International Journal of Solids and Structures 39 (5) 2002: pp. $1241-1257$. http://dx.doi.org/10.1016/S0020-7683(01)00233-5

36. Chen, S.H., Wang, T.C. Interface Crack Problems with Strain Gradient Effects International Journal of Fracture 117 (1) 2002: pp. 25-37. http://dx.doi.org/10.1023/A:1020904510702

37. Chen, S.H., Tao, C.J., Wang, T.C. A Study of SizeDependent Microindentation Acta Mechanica $167(1-2)$ 2004: pp. $57-71$. http://dx.doi.org/10.1007/s00707-003-0064-z

38. Chen, S.H., Liu, L., Wang, T.C. Small Scale, Grain Size and Substrate Effects in Nano-Indentation Experiment of FilmSubstrate Systems International Journal of Solids and Structures 44 (13) 2007: pp. 4492-4504.

http://dx.doi.org/10.1016/j.ijsolstr.2006.11.033

39. Li, H., Dong, X., Shen, Y., Diehl, A., Hagenah, H., Engel, U., Merklein, M. Size Effect On Springback Behavior Due to Plastic Strain Gradient Hardening in Microbending Process of Pure Aluminum Foils Materials Science and Engineering A 527 (16-17) 2010: pp. 4497-4504. http://dx.doi.org/10.1016/j.msea.2010.03.105

40. Lee, H., Jung, B., Kim, D., Park, H. On the Size Effect for Micro-Scale Structures Under the Plane Bulge Test Using the Modified Strain Gradient Theory International Journal of Precision Engineering and Manufacturing 12(5) 2011: pp. $865-870$. http://dx.doi.org/10.1007/s12541-011-0115-7.

41. Xiang, Y., Vlassak, J.J. Bauschinger and Size Effects in Thin-Film Plasticity Acta Materialia 54 (20) 2006: pp. $5449-5460$. http://dx.doi.org/10.1016/j.actamat.2006.06.059.

42. Chen, S.H., Wang, T.C. A New Deformation Theory with Strain Gradient Effects International Journal of Plasticity 18 (8) 2002: pp. $971-995$. http://dx.doi.org/10.1016/s0749-6419(01)00020-1

43. Liang, B.H., Hu, S.G. Plasticity of Sheet Metal Forming. China Machine Press, Beijing, 1987: pp. 123 - 163.

44. Liang, W., Yang, X.X. Second Class Size Effects on Brass Sheet in Tensile Test Journal of Plasticity Engineering 20 (01) 2013: pp. 100-107. http://dx.doi.org/10.3969/j.issn.1007-2012.2013.01.021

45. Mahabunphachai, S., Koc, M. Investigation of Size Effects On Material Behavior of Thin Sheet Metals Using Hydraulic Bulge Testing at Micro/Meso-Scales International Journal of Machine Tools and Manufacture 48 (9) 2008: pp. $1014-1029$. http://dx.doi.org/10.1016/j.ijmachtools.2008.01.006

46. Byon, S., Moon, C., Lee, Y. Strain Gradient Plasticity Based Finite Element Analysis of Ultra-Fine Wire Drawing Process Journal of Mechanical Science and Technology 23 (12) 2009: pp. 3374. http://dx.doi.org/10.1007/s12206-009-0926-y

47. Yun, W., Peilong, D., Zhenying, X., Hua, Y., Jiangping, W., Jingjing, W. A Constitutive Model for Thin Sheet Metal in Micro-Forming Considering First Order Size Effects Materials and Design 31 (2) 2010: pp. 1010-1014. http://dx.doi.org/10.1016/j.matdes.2009.07.037

48. Kim, G.Y., Ni, J., Koc, M. Modeling of the Size Effects On the Behavior of Metals in Microscale Deformation Processes Journal of Manufacturing Science and Engineering, Transactions of the ASME 129 (3) 2007: pp. 470-476. http://dx.doi.org/10.1115/1.2714582

49. Shen, Y., Yu, H.P., Ruan, X.Y. Discussion and Prediction On Decreasing Flow Stress Scale Effect Transactions of Nonferrous Metals Society of China (English Edition) 16 (1) 2006: pp. $132-136$. http://dx.doi.org/10.1016/s1003-6326(06)60023-x

50. Shu, J.Y., $\quad$ Fleck, N.A., $\quad$ Van Der Giessen, E., Needleman, A. Boundary Layers in Constrained Plastic Flow: Comparison of Nonlocal and Discrete Dislocation Plasticity Journal of the Mechanics and Physics of Solids 49 (6) 2001: pp. $1361-1395$. http://dx.doi.org/10.1016/S0022-5096(00)00074-0

51. Sciarra, G., Dell'Isola, F., Coussy, O. Second Gradient Poromechanics International Journal of Solids and Structures 44 (20) 2007: pp. 6607-6629. http://dx.doi.org/10.1016/j.jijsolstr.2007.03.003 